\title{
A Method to Assess and Reduce Pollutant Emissions of Logistic Transportation under Adverse Weather
}

\author{
Mingkong Zhang ${ }^{1,2}$, Xiaobing $\mathrm{Hu}^{3,4, *}$ and Jingai Wang ${ }^{1,2}$ \\ 1 Faculty of Geographical science, Beijing Normal University, Beijing 100875, China; \\ mingkong@mail.bnu.edu.cn (M.Z.); jwang@bnu.edu.cn (J.W.) \\ 2 Key Laboratory of Environmental Change and Natural Disasters, Ministry of Education, \\ Beijing Normal University, Beijing 100875, China \\ 3 College of Electronic Information and Automation, Civil Aviation University of China, Tianjin 300300, China \\ 4 Collaborative Innovation Center of eTourism, Beijing Union University, Beijing 100101, China \\ * Correspondence: huxb1975@163.com
}

Received: 3 October 2019; Accepted: 22 October 2019; Published: 26 October 2019

\begin{abstract}
With the increase of vehicle activities and adverse weather under the background of modernization and global warming, more attention should be paid to vehicle emissions reduction in such circumstances for environmental protection and sustainable transportation. Different from some typical measures, e.g., relevant government policies, improvement of vehicle hardware technologies, and optimization of traffic management, this paper develop a new method based on emergency path optimization to evaluate and reduce pollutant emissions of logistic transportation under adverse weather. Firstly, we establish a calculation model of pollutant emissions (LT-PE model) to calculate the amount of vehicle pollutant emissions produced under adverse weather. Then, a co-evolving path optimization (CEPO) method-based ripple-spreading algorithm is proposed in order to reduce pollutant emissions. To validate the effectiveness of the proposed method, this paper selects fruit logistics transportation affected by typhoon in China's Hainan Island as a case study. The results show that total vehicle pollutant emissions from the fruit transportation of 35 farms under the typhoon are $28.1 \%$ more than when there is no typhoon. The proposed method can reduce pollutant emissions by $21.2 \%$ compared with the traditional methods under typhoon.
\end{abstract}

Keywords: logistic transportation; vehicle pollutant emissions; adverse weather; path optimization

\section{Introduction}

The development of international trade and e-commerce has promoted the rapid growth of industrial production and people's consumption, which has driven up the logistics industry in recent decades all over world [1]. The bulletin of the Ministry of Transport of the People's Republic of China has shown that road transport is the foundational and dominant transportation, and the volume and the frequency of road cargo transportation have increased substantially from 2014 to 2018. The fast development of the logistics industry leads to more vehicle emissions. Studies shows the logistic industry has become a significant source of air pollution, which generate environment pollution and a negative impact on public health [2-7]. Carbon monoxide (CO), nitrogen oxides (NOx), hydrocarbons (HC), and particulate matter (PM) from vehicle emissions contribute a high proportion of atmospheric pollutants [8-14]. For example, haze-fog by $\mathrm{PM}_{2.5}$ has become a big concern of public health nowadays, and recent research has shown that $\mathrm{CO}$ and NOx from vehicle emissions are related to increased incidence of asthma and lung cancers [2,13]. In Europe and USA, air pollutants have adversely affected children's lung function growth [13]. In addition, global warming has increased the frequency and intensity of adverse weather events, especially tropical cycle, which has a great influence on logistic 
transportation $[13,15]$. Regions with potential high economic losses caused by tropical cycles are mainly distributed in some coastal areas of England and other developed countries in Europe, the Yangtze River Delta and Pearl River Delta in China, the Eastern coast of the United States, and the Gulf of Mexico, where there is a large amount of road cargo transportation [16]. Therefore, with the increase of adverse weather and logistics activities, a study on how to reduce vehicle pollutant emissions and keep transport efficiency under adverse weather might be helpful for environmental sustainability and human health.

The current methods for reducing vehicle emissions can be classified into three categories: Relevant government policies, improvement of motor vehicle hardware technologies, and optimization of traffic management. Policy measures include increasing the proportion of urban public transportation, encouraging the usage of low emission vehicles by adjusting purchase tax, improving emission control standards, giving a priority to improve public transportation infrastructure, and so on [17-19]. For instance, France, Germany, and Sweden have recently linked vehicle taxes in order to reduce vehicle emissions from passenger vehicles [18]. Improvement of motor vehicle hardware technologies include improving vehicle engine technologies and developing new energy vehicles [20-23]. For example, developing electric and hybrid electric vehicles to improve engine fuel efficiency, and autonomous vehicles to improve eco-traffic. Optimizing traffic management measures is mainly about intelligent traffic control methods [24-28]. The research shows that reducing the delay time and the number of stops at intersections by controlling traffic signals on an urban route network can reduce vehicle emissions [27]. Furthermore, now there are also studies that focus on driving behaviors to reduce vehicle emissions and propose a concept of eco-driving related to driver behaviors [29,30]. Numerous studies have proved that driver training led to effective vehicle emissions reduction [29]. Eco-driving can be divided into static and dynamic. The concept of static eco-driving can be considered as a strategy of changing driving behaviors by providing general static advices to drivers, in order to avoid fault operations (such as brake, cold boot, and over speed), reduce congestion, smoothen traffic flow, save fuel, and lower vehicle emissions. In the concept of dynamic eco-driving, navigation advices are given to drivers according to the changes in traffic conditions in real-time. This dynamic strategy takes advantage of real-time traffic sensing and traffic management system to monitor traffic speed, density, and flow, and then communicates advices in real-time back to drivers. However, little attention has been paid to the relationship between vehicle emissions and traveling distance under adverse weather.

In this paper, as with the eco-driving method, we are mainly concerned with the path optimization of multiple vehicles of long distance cargo transport for drivers within a large geographical region to reduce vehicle emission under adverse weather. In general, the goal of emergency path optimization under adverse weather mainly focuses on travelling safety. The emergency path optimized in this paper cannot only ensure travelling safety, but more importantly, it can also help to reduce vehicle pollutants emission. Adverse weather such as rainstorm, snow, or fog make route conditions more complicated than usual, e.g., wet/ice surface, high wind, and cause route network to change, so path planning under normal weather is actually a static path optimization (SPO) problem. On the contrary, it is a dynamic path optimization (DPO) problem to optimize the emergency path by using the forecast information about adverse weather, because some nodes and/or links of route network might temporarily become inaccessible due to adverse weather. Now, there are many algorithms for DPO [31-40]. Once the road network changes due to adverse weather, traditional DPO methods usually have to conduct real-time online re-optimization of travelling path. However, these traditional DPO methods can hardly lead to optimal actual travelling trajectory [41], because such DPO methods usually ignore, within a single run of online re-optimization, the predictability of routing environmental dynamics. Traditional DPO methods might go far around to avoid those areas affected by adverse weather, so it could increase pollutant emissions and travelling time, and increased travelling time will not only cause the cargo to be not delivered on time, but also increase travelling risk due to long exposure time to adverse weather. Therefore, how to achieve pollutant emissions reduction while ensuring logistic punctuality and travelling safety under adverse weather by optimizing paths for multiple vehicles of long distance 
cargo transport is the aim of this paper. Recently, a new evolutionary computation method has been reported; given that the weather forecast is accurate, it will need no online re-optimization, and can achieve the optimal actual travelling trajectory from origin to destination. The new method is called a co-evolving path optimization (CEPO), which allows co-evolving weather conditions in a single run of offline path optimization [41,42]. In this paper, we will modify the CEPO method to develop a new, effective pollutant emission reduction method for multiple vehicles of long-distance cargo transport under adverse weather.

The remainder of this paper is organized as following. Section 2 gives problem and method descriptions. Section 3 introduces the logistic transportation of fruit yields in the Hainan province of China as a case study. Section 4 conducts experiments with a typhoon scenario and then analyzes the experimental results. The paper ends with some conclusions in Section 5.

\section{Problem and Methods}

\subsection{Methodological Framework}

Here, we describe a methodological framework to investigate whether $\mathrm{HC}, \mathrm{CO}$, and NOx emissions from vehicles of logistic transportation under adverse weather will increase, how much it will increase, and whether there is any effective method to reduce such increase.

In this study, we only consider vehicles of logistic transportation; in particular, vehicles of long-distance cargo transport within a large geographical region. This is because (i) vehicles of public transportation have fixed routes, which usually will not change under adverse weather, (ii) private vehicles are less predictable under adverse weather (e.g., drivers might change their travelling paths or not, might choose public transportation instead, or even might cancel their travelling plans), while (iii) vehicles of logistic transportation have to deliver cargo as scheduled anyway, no matter the weather is good or bad, and if bad, drivers can often change their travelling paths, in order to deliver cargo as timely as possible. Changing travelling path usually means that path length will change. As is well known, vehicle emissions have a strong correlation with travelling path length. Therefore, an intuitive feeling is that under adverse weather, the exhaust emissions from logistic transportation will change. However, the question concerns how it will change-increase or decrease?

As previously explained, unlike either private vehicles (whose journey could be cancelled under adverse weather) or public transportation vehicles (which usually cannot change routes), vehicles of logistic transportation have to deliver cargo as scheduled anyway, and they have the freedom to choose and change their travelling paths. In this paper, we consider adverse weather as the only reason causing drivers to change their paths, and all other factors such as accidents, traffic jam, and route maintenance will be ignored for the sake of simplicity and focus. In this study, we will calculate vehicle pollutant emissions simply based on vehicle type, travelling speed, and path length, and ignore vehicle pollutant emissions related to brake, cold boot, and acceleration/deceleration. In addition, vehicle pollutant emissions are also related to road conditions (road type, road slope), and they are taken into account by vehicle emission factors [43].

To study changes in vehicle pollutant emissions under adverse weather, we need to build a calculation model of vehicle pollutant emissions, which is related to travelling path, then to find out how vehicles of logistic transportation plan their travelling paths. Basically, logistic transportation aims to make as many deliver journeys as possible, which means the driver will normally choose the path of minimal travelling time. Under adverse weather, the path of minimal travelling time also implies the least risk because of exposure to adverse weather. Therefore, in this paper, for a given area, we will first find out the shortest path in terms of travelling time under normal weather for each vehicle of logistic transportation in the area (online re-optimization (OLRO) method is used for calculating the path of minimal travelling time under normal weather), and calculate the associated vehicle pollutant emissions. Second, for a given adverse weather event, we will use three methods, by taking into account the impact of weather on route network, to calculate new shortest paths for vehicles 
of logistic transportation, and then assess the associated vehicle pollutant emissions (path optimization under adverse weather is solved by a modified SPO (MSPO) method, online re-optimization (OLRO), and CEPO method, respectively, of which MSPO and OLRO are widely adopted in practice). There are three indicators for evaluating the path optimized by a method, namely travelling time (TT), path length (PL), and pollutant emissions (PE). TT indicates travelling safety and transportation efficiency, because the longer the travelling time is, the greater the travelling risk is under adverse weather. PL and PE reflect transportation costs and vehicle pollutant emissions. At last, based on the three indicators, we compare between normal weather and adverse weather, and between different path optimization methods, in order to see whether vehicle pollutant emissions under adverse weather will increase, and which method is more suitable for reducing the increase in vehicle pollutant emissions.

The methodological framework of this study is illustrated in Figure 1, where LT-PE stands for the calculation model of pollutant emissions (PE) about logistic transportation (LT).

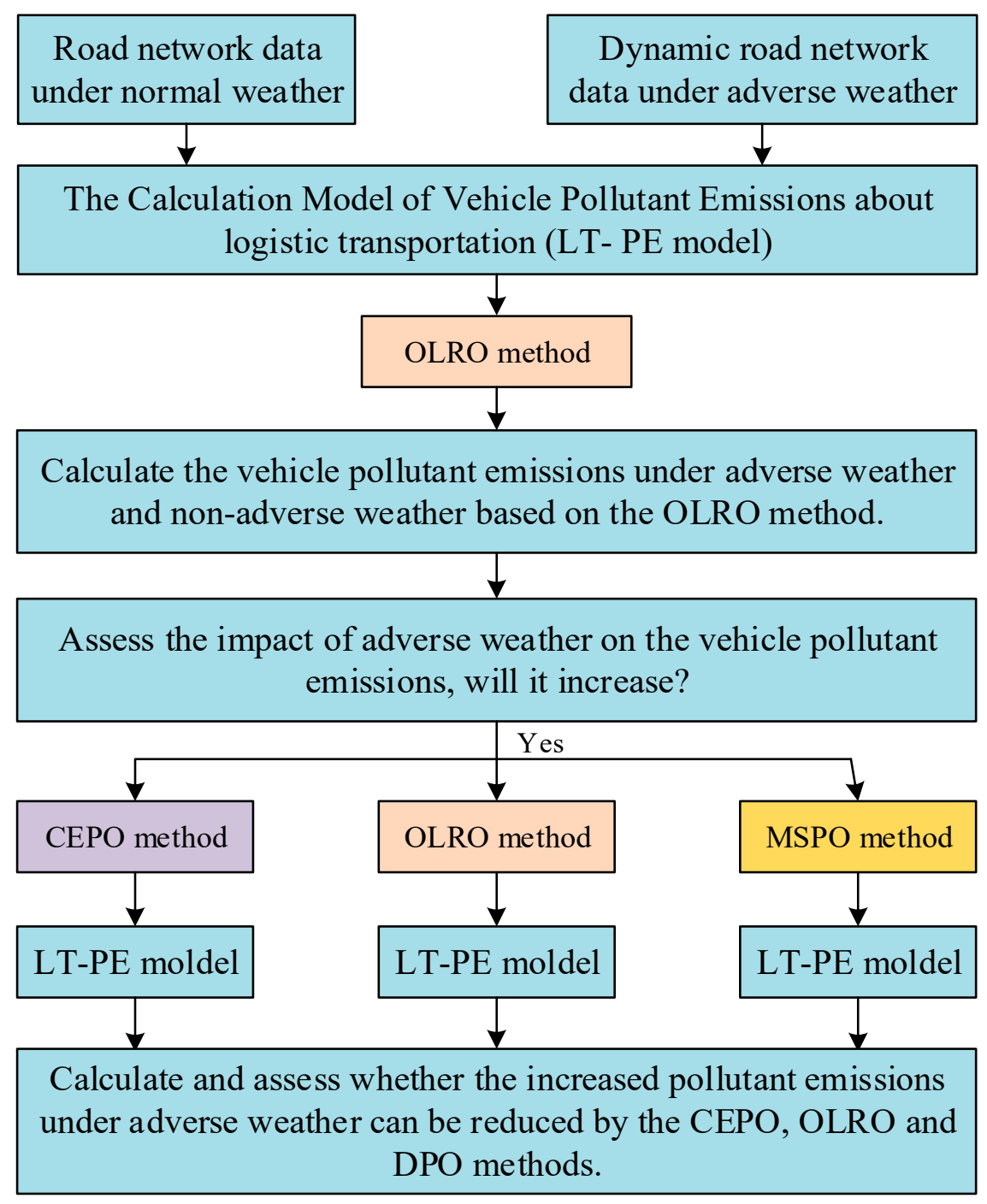

Figure 1. The methodological framework of this study.

\subsection{Calculation Model of Vehicle Pollutant Emissions}

Suppose in a given area, there are $N_{v}$ vehicles of logistic transportation that have to deliver cargo between $N_{o}$ origins and $N_{d}$ destinations. Assume a vehicle $v$ needs to deliver cargo from origin $O_{v}$ and destination $D_{v}, v=1, \ldots, N_{v}$. The type of vehicle $v$ is $T_{v}, T_{v}=1$ represents the type of gasoline/diesel small vehicle, $T_{v}=2$ the type of gasoline/diesel medium-size vehicle, $T_{\mathrm{v}}=3$ the type of gasoline/diesel 
heavy vehicle, and $T_{v}=0$ the type of vehicle that does not have different specific displacement. $L_{v}$ is the path length for vehicle $v$ to travel between origin $O_{v}$ and destination $D_{v}$, which is calculated by a path optimization method. $F\left(T_{v}\right)$ is the emission factor of vehicle type $T_{v}$. HC, NOx, and CO are the main pollutant exhaust for calculating pollutant emissions from motor vehicles. The calculation model of vehicle emissions for multiple vehicles of long distances cargo transport is as follows.

For a vehicle $v$ of type $T_{v}$ that departs from origin $O_{v}$ to destination $D_{v}, v=1, \ldots, N_{v}$, its vehicle emission factor $F\left(T_{v}\right)$ and optimized path length $L_{v}$ can be calculated as

$$
\begin{gathered}
F\left(T_{v}\right)=f_{H C}\left(T_{v}\right)+f_{C O}\left(T_{v}\right)+f_{N O_{X}}\left(T_{v}\right) \\
L_{v}=f_{P O A}\left(O_{v}, D_{v}\right)
\end{gathered}
$$

where $f_{\mathrm{HC}}, f_{\mathrm{CO}}$, and $f_{\mathrm{NOx}}$ are functions to determine the $\mathrm{CO}$ emission factor, $\mathrm{NO}_{\mathrm{x}}$ emission factor, and HC emission factor of $T_{v}$, respectively, and $f_{\text {POA }}$ represents a path optimization method.

The vehicle emissions from a single journey of vehicle $v$ are:

$$
P_{v}=L_{v} \times F\left(T_{v}\right)
$$

Since there are $N_{v}$ vehicles, the total vehicle emissions from multiple vehicles of logistic transportation are:

$$
P=\sum_{v=1}^{N_{v}} P_{v} .
$$

Based on the above model, we need to determine vehicle emission factors $F\left(T_{v}\right)$ of a vehicle and path optimization algorithm $f_{P O A}$.

Vehicle emission factor $F\left(T_{v}\right)$ is the quantity of gas produced by motor vehicle when it travels one kilometer, and the unit is $\mathrm{g} / \mathrm{km}$. Therefore, we can calculate path length to assess vehicle emissions. The determination of emission factors in this paper is borrowed from the work of Xie et al. [43].

Regarding methods of optimizing travelling path $\left(f_{P O A}\right)$, in this paper, we introduce three methods, which include the modified static path optimization (MSPO) method, the online re-optimization (OLRO) method, and the co-evolving path optimization (CEPO) method. The MSPO method and the OLRO method are two well-known methods in practice for path planning under adverse weather. Firstly, we modify a SPO method to solve dynamic path optimization, and this method is called modified SPO (MSPO). One method does not re-plan travelling path, but still sticks to the best path of SPO and simply introduces waiting behavior if the best path of SPO is blocked by adverse weather. When the initial shortest path is closed due to adverse weather, the MSPO method simply introduces waiting behavior until the initial shortest path becomes accessible again. The MSPO method might be friendly to vehicle emissions reduction, but the exposure time and associated risk could increase. The second method is OLRO, which mainly conducts online re-optimization according to the latest condition of route network. Basically, OLRO aims to get to the destination as soon as possible, and it does not allow waiting behavior. When the route network changes under adverse weather, the OLRO method has to conduct online recalculation according to the new route network. It might reduce the exposure risk as the resulted travelling time could be shorter than that of MSPO method under adverse weather. Since travelling time and vehicle emission are two major concerns to vehicles of logistic transportation under adverse weather, we will report a new method in this paper, so-called co-evolving path optimization (CEPO), which can combine merits of MSPO and OLRO.

\subsection{Mathematical Descriptions of MSPO, OLRO, and CEPO}

Let a route network be denoted as $G(V, E)$, which is composed of node set $V$ and link set $E$. $V$ has $N_{\mathrm{N}}$ different nodes including the origins and the destinations, and $E$ has $N_{\mathrm{L}}$ links between nodes. An $N_{N} \times N_{N}$ adjacency matrix $M$ is used to record the route network. $M(i, j)=1, i=1, \ldots, N_{N}$ and $j=1$, 
$\ldots, N_{\mathrm{N}}$, means there is a link between node $i$ and node $j . M(i, j)=0$ means no link between node $i$ and node j. $S_{\mathrm{L}}(i, j)$ indicates a speed limit on link $M(i, j) . C(i, j)$ is cost matrix associated with link $M(i, j)$, which tells, at the speed of $S_{\mathrm{L}}(i, j)$, how much time it will take to travel through the link $M(i, j)$.

Vector $R$ records a candidate path, in which element $R(i)=j$ means node $j$ is the $i$ th node in the path, $i=1, \ldots, N_{\mathrm{P}}$, and $j=1, \ldots, N_{\mathrm{N}}, N_{\mathrm{P}}$ tells the total numbers of nodes in the candidate path, including the origin and the destination,. Obviously, $R(1)$ is the origin and $R\left(N_{\mathrm{P}}\right)$ is the destination. In this study, no loop is allowed, which means no node can appear in a path for more than once, i.e.,

$$
R(i) \neq R(j) \text {, if } i \neq j, i=1, \ldots, N_{P} \text {, and } \mathrm{j}=1, \ldots, N_{P} \text {. }
$$

For the sake of simplicity but without losing generality, suppose we need to perform a path optimization at time $t=0$. Based on a given forecasted weather dynamics, we can predict route network $M$ status in future time instants. $M_{k \mid 0}$ expresses the predicted adjacency matrix for the future time $t=k$, and the prediction about $M_{k \mid 0}$ is made at the current time $t=0$.

A single run of OLRO method aims to resolve the following minimization problem,

$$
\min _{R \in \Omega} f_{O L R O}\left(R, N_{P}\right)
$$

subject to Constraint (5) and

$$
M_{0}(R(i), R(i+1))=1, \text { for } i=1, \ldots, N_{\mathrm{P}}-1
$$

where $\Omega$ is the set of all possible paths connecting the origin and the destination,

$$
\begin{gathered}
f_{\mathrm{OLRO}}(R, 1)=0 \\
f_{\mathrm{OLRO}}(R, i)=f_{\mathrm{OLRO}}(R, i-1)+C(R(i-1), R(i)), 1<i \leq N_{\mathrm{P}} .
\end{gathered}
$$

Clearly, Equation (7) shows that during the single run of OLRO method at time $t=0$, the route network is always fixed as measured at time $t=0$. Thus, once the route network changes due to adverse weather at a real future time $t=k>0$, the OLRO method has to re-conduct a new single run of optimization based on $M_{k}$, which is the adjacency matrix measured at the real time $t=k$. In other words, when the route network changes at the real time $t=k$, the OLRO method simply replaces $M_{0}$ with $M_{k}$ in Equation (7), and then repeats resolving the minimization problem defined by Equations (6)-(9).

The MSPO method can be viewed as a special case of the OLRO method, because the MSPO method resolves the minimization problem defined by Equations (6)-(9) only once at the initial time $t=0$ based on $M_{0}$, and the path optimized at time $t=0$ will be followed strictly, no matter how the route network changes in future, i.e., no matter what $M_{k}$ is at the real time $t=k>0$. When following the optimized path of time $t=0$, if at the real time $t=k$, the vehicle arrives at a node/link of the optimized path, and if the node/link happens to become inaccessible at time $t=k$ due to adverse weather, then the vehicle has to wait at the node/link until the node/link becomes accessible again in farther future. It should be emphasized that if the OLRO method is adopted, then the traveler will not have any wait behaviors, because once the accessibility of a node/link changes due to adverse weather, the OLRO method will repeat its online optimization based on the latest $M_{k}$, and then provides a newly optimized path for the vehicle to follow.

According to Equation (7), we know the OLRO method recalculates the optimal travelling path online once there is a change in the routing network, therefore it does not have waiting behavior. Conversely, the MSPO method does not need online re-calculation, but simply introduces waiting behavior to the path optimized by the OLRO method at time $t=0$ based on $M_{0}$.

Largely different from the OLRO and MSPO methods, a single run of CEPO aims to resolve the following minimization problem

$$
\min _{R \in \Omega} f_{C E P O}(R, L(R))
$$


subject to

$$
\begin{gathered}
M_{k \mid 0}(R(i), R(i+1))=1, k=k_{i}, \ldots, k_{i+1} \\
f_{C E P O}(R, 1)=0 \\
f_{C E P O}(R, i+1)=\max \left(f_{C E P O}(R, i), k_{i} \mid 0\right)+C(R(i), R(i+1)), 1 \leq i<N_{P}-1
\end{gathered}
$$

where $f_{\mathrm{CEPO}}(R, i)$ is a function calculating the travelling time to pass the $i$ th node in path $R$ when travelling along path $R, k_{i}$ is the time when node $R(i)$ is predicted to be accessible after reached along path $R, M_{k \mid 0}(R(i), R(i+1))=1$ means that, according to the prediction made at the initial time $t=0$, nodes $R(i)$ and $R(i+1)$ are directly connected at time $t=k \mid 0$.

Equations (11)-(13) clearly show that both the connectivity and travelling time of a sub-path in $R$ are dependent of when the sub-path is to be travelled through, which is not considered in the OLRO method. Changes in $M_{k \mid 0}$ over predicted travelling time $k \mid 0$ are determined by the evolving dynamics of adverse weather, which may be formulated as following in general:

$$
M_{k+1 \mid 0}=f_{F A W D}\left(M_{k \mid 0}\right), k \geq 0
$$

subject to $M_{0 \mid 0}=M_{0}$, where $f_{F A W D}$ is the dynamical function associated with the forecasted adverse weather dynamics, and $M_{0}$ is the adjacency matrix measured at time $t=0$.

Equations (10)-(14) show that, if $f_{\text {FAWD }}$ is given at the initial time $t=0$, the CEPO method can conduct a one-off optimization to find the best path $R$ under the given time-varying route network. Comparing Equation (7) of OLRO and Equation (11) of CEPO, we can see that, in a single run of optimization, the OLRO and MSPO methods focus on whether or not there is a link between two nodes, while the CEPO considers when a link can pass, in other words, whether or not a link can pass at right time.

Compared with the OLRO and MSPO methods, the CEPO method does not need online re-optimization, but at time $t=0$, it takes into account a given routing environmental dynamics (rather than just $M_{0}$ in the MSPO method) when optimizing the travelling path, and waiting behaviors may be necessary if they can save travelling time.

\subsection{The Realization of CEPO}

The realization of CEPO is based on the ripple-spreading algorithm (RSA). The RSA is a decentralized, multi-agent-based, bottom-up simulation model [41], which gives the RSA a great flexibility for modifications. RSA is developed for various path optimization problems [44,45]. In this paper, we modify the RSA for solving CEPO under adverse weather. First, integrate and update route network matrix $M$ into the ripple relay race. Secondly, set different ripple spreading speeds along different links. Lastly, introduce a waiting behavior for ripples, when a node/link is closed due to adverse weather, waiting before the closed node/link might save travelling time, length, or risk.

The flowchart of modified RSA for the CEPO is given in Figure 2. Suppose the network has $N_{N}$ nodes in total, node 1 is origin, node $N_{\mathrm{N}}$ is destination. If there is a link between node $\mathrm{n}$ and node $\mathrm{m}$, $S_{\mathrm{L}}(n, m)$ is the speed limit on the link. In the ripple relay race, each node has just one ripple, and the ripple of node $\mathrm{i}$ is called ripple $i . F_{\mathrm{R}}(\mathrm{i})=j>0$ means that node $i$ has been activated by ripple $j . r_{\mathrm{R}}(i$, :) denotes the current radiuses of ripple $i$ along those links, which connect to node $i$. $S_{\mathrm{R}}(i)$ records the state of ripple $i$, and $S_{\mathrm{R}}(i)=0,1,2,3$ means ripple $i$ is inactive, waiting, active, and dead, respectively.

In the flowchart of Figure 2, Step 3.2 to Step 3.4 represent the co-evolving relationship between the time-varying route network and ripples spreading process. Step 3.5 defines that, once an accessible and un-activated node is arrived by any incoming ripple at the first time, a new active ripple will be activated at the node and spread out immediately. Step 3.4 and Step 3.5 set ripple spreading speeds on a link, which is dependent on the link level. Step 3.6 sets the waiting behavior of ripples; if a blocked node is first reached by an incoming ripple, a new ripple will be immediately activated by this node and wait here. Step 3.7 will eliminate any ripple whose connected nodes have all been reached. 


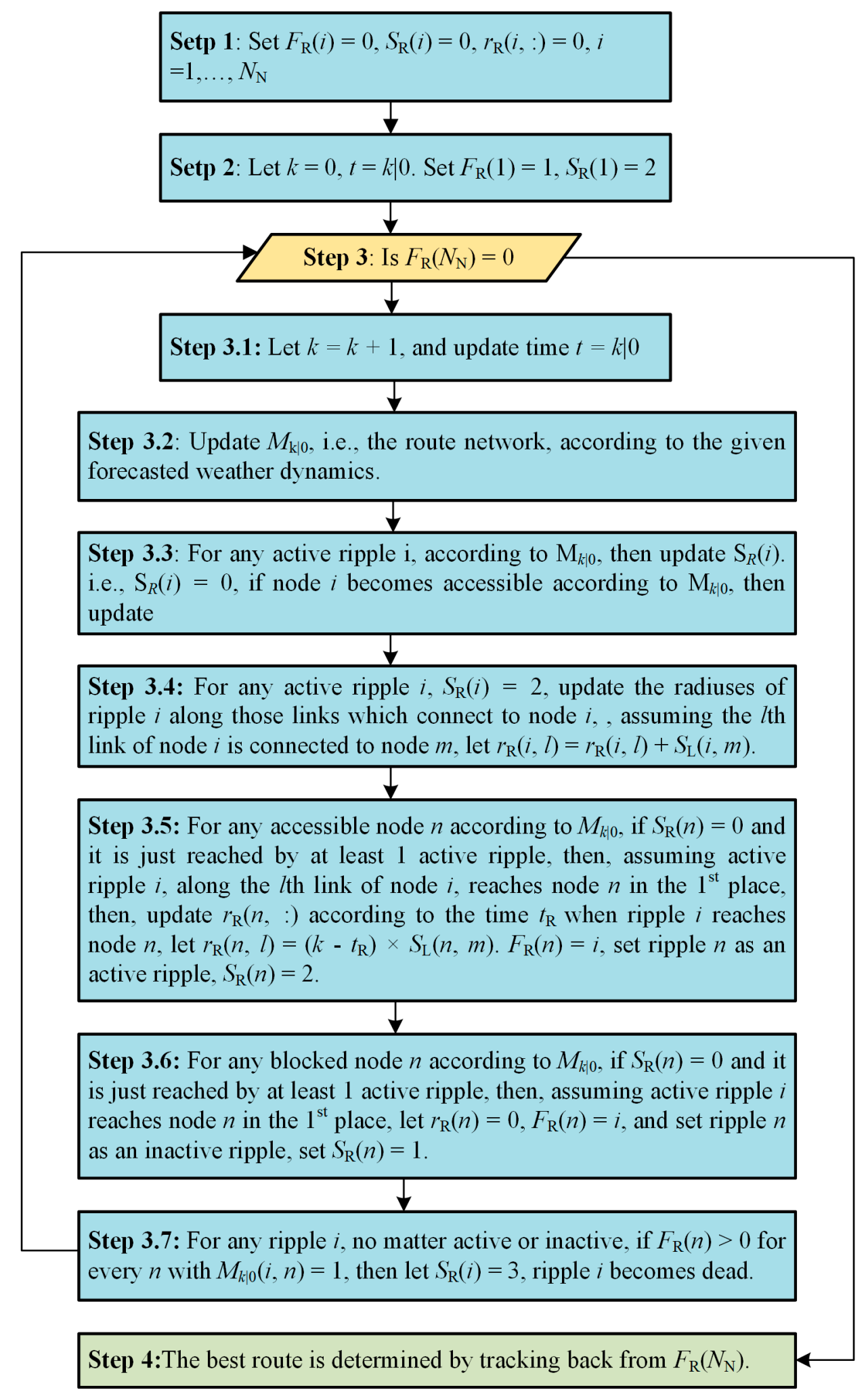

Figure 2. Flowchart of ripple-spreading algorithm (RSA) for co-evolving path optimization (CEPO).

\section{Case study}

Based on the problem description of Section 2, to assess vehicle emissions of logistic transport under the OLRO, MSPO, and CEPO methods, we choose the fruit transportation in Hainan island of China in typhoon scenarios as a case study. 


\subsection{Fruit Transportation in Hainan Island}

Hainan island is located in the tropical region, and this makes its fruit production an important economic industry. The map of Hainan island in 2016 shows that there are 35 farms exporting fruits by those ports of Hainan island year around. Currently, Hainan province has five ports distributed in four directions [46]. Haikou port is the biggest port with advanced equipment and facilities. Most fruits will be exported by Haikou port. Normally, trucks of these farms for fruit transportation have to deliver fruits as scheduled anyway, regardless of whether the weather is good or bad. In the case of adverse weather, drivers can often change their travelling paths accordingly, in order to deliver fruits as timely as possible and guarantee the timeliness of logistics transportation.

\subsection{Adverse Weather Condition-Typhoon}

Hainan island suffers from Pacific typhoons every year. Wet pavement, impaired visibility, and high wind caused by heavy typhoon increase risks to drives and the vehicles. Thanks to recent advances in typhoon forecasting technologies, typhoon center moving trajectory, heavy rain, and hurricane areas can be forecasted with a satisfactory accuracy for a few hours. Making full use of typhoon forecasting technologies has played a crucial role in improving the transport emergency response capability under adverse weather. Most scholars studied the area affected by typhoon storms and winds by delimiting buffer circles $[47,48]$. In this paper, circular areas with typhoon center as the center and with different wind speed-associated radiuses are treated as dangerous areas, or called typhoon wind rings, where heavy wind and rainfall will prevent vehicles from traveling safely. As a result, the route will be closed or vehicle speed will be reduced in typhoon wind rings. The specific classification criteria for typhoon wind rings can be found in Section 4.1 about experiment setup.

\subsection{Route Network System}

The Hainan island, the second largest island in China, has a relatively modern road network, which includes four categories of roads: Highway, national route, provincial route, and county-level route connecting towns and villages, as shown in Figure 4. In addition, the route network of Hainan is completely isolated from the route network of mainland China, and there is no external route available, so this makes it a perfect test case for studying path optimization.

\subsection{Determination of Emission Factors (F)}

HC, NOx, and CO emission factors are mainly referred to in the work of [43], which is about the calculation of the pollutant emission factors in Hainan. The latest MOVES2014a model of the US Environmental Protection Agency was adopted and then modified to obtain vehicle exhaust emissions in Hainan. The basic input parameters of the model include time and space settings, vehicle type, vehicle ownership and age distribution, average vehicle speed distribution, annual mileage and mileage distribution, fuel parameters, and meteorological parameters. The parameter of average vehicle speed distribution also takes into account the impact of various road conditions (e.g., road slope, road type, weather) [43]. Therefore, $\mathrm{HC}, \mathrm{NOx}$, and $\mathrm{CO}$ emission factors are the mean of vehicle emissions per kilometer taking into account all these factors.

Long-distance fruit transportation is usually conducted by refrigerated trucks. According to displacement, there are mainly three types of refrigerated trucks, so only the emission factor of light diesel vehicles, the emission factor of medium-sized diesel vehicles, and the emission factor of heavy-duty diesel vehicles are needed, as shown in Table 1. 
Table 1. Motor vehicle emission factors unit: $\mathrm{g} / \mathrm{km} \mathrm{[43].}$

\begin{tabular}{cccccc}
\hline \multicolumn{2}{c}{ Types of Motor Vehicles } & CO & HC & NO $_{x}$ & $T_{v}$ \\
\hline \multirow{3}{*}{ Displacement $>$ 1 liter } & Light diesel vehicles & 1.682 & 0.428 & 1.12 & 1 \\
\cline { 2 - 6 } & Medium-sized diesel vehicles & 2.268 & 0.428 & 3.48 & 2 \\
\cline { 2 - 6 } & Heavy duty diesel vehicle & 3.823 & 0.742 & 5.882 & 3 \\
\hline
\end{tabular}

\section{Simulation and Results}

\subsection{Experiment Setup}

We conduct experiments by the above three methods under two scenarios: One without typhoon and the other with typhoon. Evaluation indicators of the three path optimization methods are travelling time (TT), path length (PL), and pollutant emissions (PE). About typhoon scenario, Wenzhou typhoon official website provides accurate information of moving trajectory, center moving speed, and wind speed of each typhoon affecting China. We extract all moving trajectories of typhoons landing on Hainan island and their landing points in Hainan island, as shown in Figure 3.

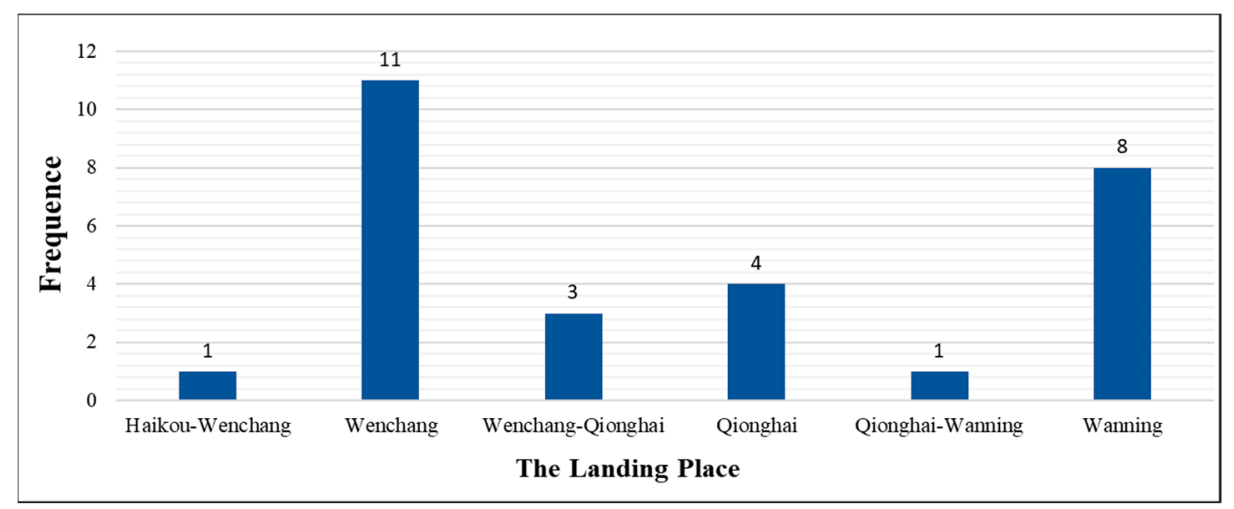

Figure 3. The landing point distribution of typhoons in Hainan island from 1957 to 2006.

It should be noted that the impacts of typhoon on road are uncertain. According to the grade of weather conditions for freeway transportation issued by China meteorological administration, when the wind power reaches level $11(28.5 \mathrm{~m} / \mathrm{s})$, it will have a serious impact on road traffic, causing the road to be closed [49]. If the wind power is between level 9 and level $10(20.8 \mathrm{~m} / \mathrm{s} \sim 28.4 \mathrm{~m} / \mathrm{s})$, vehicles have to reduce speed significantly for safety reasons, and between level 7 and level $8(17.1 \mathrm{~m} / \mathrm{s} \sim 20.7 \mathrm{~m} / \mathrm{s})$, vehicles should also slowdown more or less. Therefore, for driving safety, we consider reducing the speed of driving or closing road in different typhoon affecting areas, and classify a typhoon covered area into three wind rings. The area with wind power greater than or equal to level 11 is the first wind ring, between level 9 and level 10 is the second wind ring, and between level 7 and level 8 is the third wind ring. We introduce three parameters, i.e., $\alpha 1, \alpha 2, \alpha 3$, as coefficients of speed reduction in the three wind rings, and $\alpha 1>\alpha 2>\alpha 3, \alpha 1, \alpha 2, \alpha 3 \in[0,1]$. Within the first ring, vehicle speed needs to be reduced by $\alpha 1 \%$ for safety purposes; within the second ring, vehicle speed needs to be reduced by $\alpha 2 \%$; and within the third ring, vehicle speed needs to be reduced by $\alpha 3 \%$. Beyond the third ring, a vehicle can travel as normal. Of course, not all typhoons will have three wind rings as discussed above; we can modify those relevant parameters according to actual typhoon conditions. This consideration of different rings can be integrated into the typhoon model as well as the path optimization algorithm.

By analyzing the landing points and travelling trajectories of typhoons in Hainan island, we find that most typhoons moved to west or northwest after landing on Hainan island. So, in the experiment, we simulate a historical and representative typhoon, which landed at Wanning city and moved to northwest of Hainan island at a speed of $20 \mathrm{~km} / \mathrm{h}$. Based on advanced weather forecasting 
technologies, we can get typhoon information every hour and typhoon intensity, including typhoon moving direction, speed, and the maximum radius of wind ring. The simulated typhoon intensity is a super typhoon, which has a strong disturbance to the normal operation of the route network. In the case study, we set $\alpha 1=1, \alpha 2=0.6, \alpha 3=0.3$, and the first wind ring radius of typhoon is set to $20 \mathrm{~km}$, the second wind ring radius to $25 \mathrm{~km}$, and the third wind ring radius to $30 \mathrm{~km}$, as illustrated in Figure 4 . The routes are closed in the first wind ring and vehicle speed down to zero. Regarding speed limit setting, we assume that the average speed of a vehicle is $80 \mathrm{~km} / \mathrm{h}$ in highway, $60 \mathrm{~km} / \mathrm{h}$ in the national route system, $40 \mathrm{~km} / \mathrm{h}$ in the provincial route system, and $20 \mathrm{~km} / \mathrm{h}$ in county roads. The four categories of roads, the moving trajectory of typhoon, and fruit farm distribution in Hainan island are shown in Figure 4.

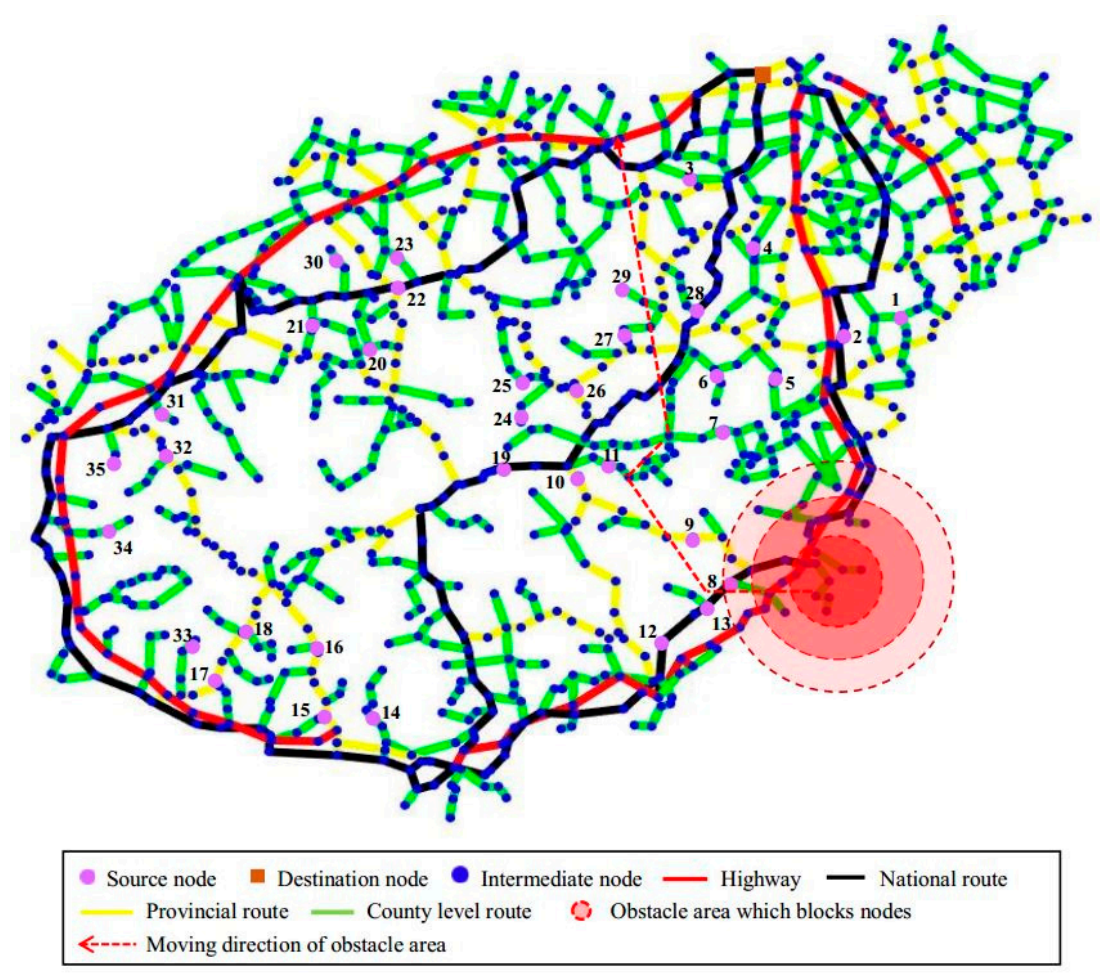

Figure 4. The typhoon moving path and the route network of Hainan island.

\subsection{Experiments to Verify Whether Vehicle Emissions Increase under Adverse Weather}

In this experiment, we aim to explore whether vehicle emissions of logistic transportation under adverse weather will increase. Thirty-five fruit farms in the Hainan island are the origins, and the destination is Haikou port. Each farm sends a light diesel vehicle, a medium-sized diesel vehicle, and a heavy-duty diesel simultaneously, transporting fruits to Haikou port. When there is no typhoon landing on Hainan island, the route network is not affected by the weather, and the path planning is a static path optimization problem. As described in Section 2.1, logistic transportation aims to choose the path of minimal travelling time in general. In this sub-section, we adopt the OLRO method to optimize travelling time from each origin without typhoon landing on Hainan island, and then use the same method to re-calculate travelling path in the typhoon scenario for comparative purposes. Figure 5 gives the results of single path optimization from Licai farm to Haikou port in two scenarios. Table 2 is the results of path optimization about each farm in two scenarios by the OLRO method.

Figure 5 shows the different results of path optimization in a single journey of fruit transportation in two scenarios (i.e., without typhoon and with typhoon). The driver chooses the fastest travelling path without typhoon as shown in Figure 5a. However, when the typhoon lands at Wanning city, the initial travelling path will be covered by the typhoon. To avoid the typhoon area, a new travelling path 
is recalculated online by the OLRO method as shown in Figure 5b. According to Table 2, the typhoon will affect the fruit transportation of some farms and cause a significant increase in travelling path compared with no typhoon. Under the OLRO method, total travelling path from the fruit transportation of 35 farms under the typhoon is $28.1 \%$ longer than when there is no typhoon, total travelling time for the fruit transportation of 35 farms in the typhoon scenario is $33 \%$ more than no typhoon, and as a result, total emissions in the typhoon scenario are $28.1 \%$ more than no typhoon. The results show that optimizing travelling path under typhoon may provide a new pathway for improving pollutant emissions reduction of logistic transportation under adverse weather.

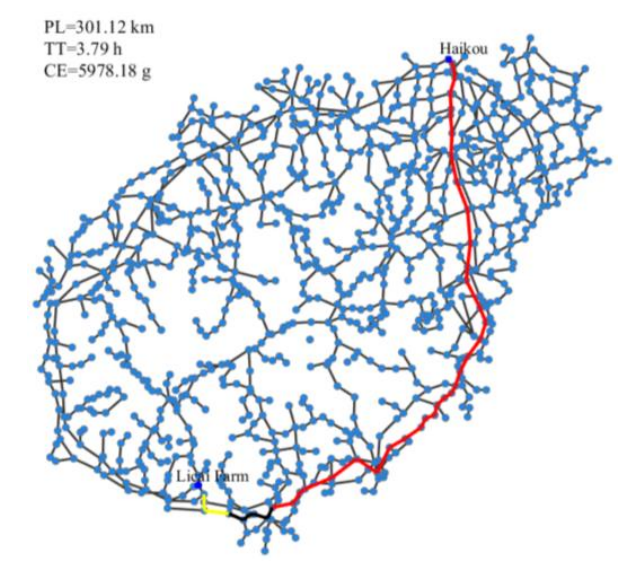

(a)

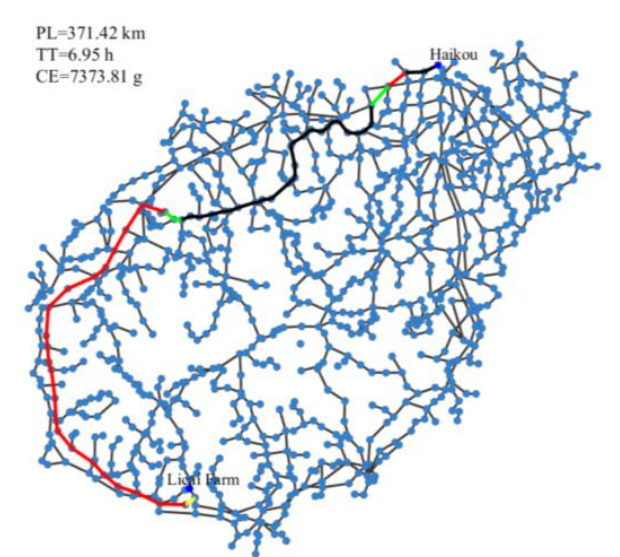

(b)

Source $\square$ Destination $\longrightarrow$ County level route $\quad$ Provincial route $\longrightarrow$ National route
Highway Typhoon

Figure 5. The optimization results of travelling path by the online re-optimization (OLRO) method: (a) The optimization result of travelling path by the OLRO method without typhoon; (b) the optimization result of travelling path by the OLRO method under typhoon.

Table 2. Total emissions and total travelling time from 35 farms in two scenarios.

\begin{tabular}{|c|c|c|c|c|c|c|c|c|}
\hline & \multirow{2}{*}{$\begin{array}{c}\text { Farm } \\
\text { Number }\end{array}$} & \multirow{2}{*}{$\begin{array}{l}\text { Farm } \\
\text { Name }\end{array}$} & \multicolumn{3}{|c|}{ No Typhoon } & \multicolumn{3}{|c|}{ Typhoon } \\
\hline & & & PL/km & $\mathrm{TT} / \mathrm{h}$ & $\mathrm{PE} / \mathrm{g}$ & PL/km & $\mathrm{TT} / \mathrm{h}$ & $\mathrm{PE} / \mathrm{g}$ \\
\hline \multirow{14}{*}{$\begin{array}{l}\text { Farms whose fruit } \\
\text { transpor-tation is } \\
\text { not affected by } \\
\text { typhoon }\end{array}$} & 1 & Sanjiaoting & 92.07 & 1.63 & 1833.71 & 92.07 & 1.63 & 1833.71 \\
\hline & 3 & Jinan & 48.31 & 1.00 & 962.15 & 48.31 & 1.00 & 962.15 \\
\hline & 4 & Jinjiling & 57.16 & 1.03 & 1138.51 & 57.16 & 1.03 & 1138.51 \\
\hline & 7 & Dongtai & 133.87 & 2.50 & 2666.16 & 134.97 & 3.05 & 2688.05 \\
\hline & 8 & Xinglong & 163.57 & 2.06 & 3247.33 & 163.57 & 2.06 & 3247.33 \\
\hline & 9 & Xinzhong & 176.37 & 2.51 & 3512.73 & 176.37 & 2.51 & 3512.73 \\
\hline & 12 & Lingmen & 186.38 & 2.52 & 3712.05 & 186.38 & 2.52 & 3712.05 \\
\hline & 13 & Nanlin & 172.03 & 2.28 & 3426.21 & 172.03 & 2.28 & 3426.21 \\
\hline & 14 & Nandao & 289.59 & 3.98 & 5767.63 & 289.59 & 3.98 & 5767.63 \\
\hline & 16 & Baoguo & 317.33 & 4.47 & 6320.11 & 317.33 & 4.47 & 6320.11 \\
\hline & 21 & Zhubijiang & 179.75 & 2.93 & 3580.04 & 179.75 & 2.93 & 3580.04 \\
\hline & 31 & Hongquan & 195.82 & 2.75 & 3900.02 & 195.82 & 2.75 & 3900.02 \\
\hline & 34 & Gongai & 246.21 & 3.36 & 4887.93 & 246.21 & 3.36 & 4887.93 \\
\hline & 35 & Datian & 232.34 & 3.26 & 4627.43 & 232.34 & 3.26 & 4627.43 \\
\hline
\end{tabular}


Table 2. Cont.

\begin{tabular}{|c|c|c|c|c|c|c|c|c|}
\hline & \multirow{2}{*}{$\begin{array}{c}\text { Farm } \\
\text { Number }\end{array}$} & \multirow{2}{*}{$\begin{array}{l}\text { Farm } \\
\text { Name }\end{array}$} & \multicolumn{3}{|c|}{ No Typhoon } & \multicolumn{3}{|c|}{ Typhoon } \\
\hline & & & $\mathrm{PL} / \mathrm{km}$ & $\mathrm{TT} / \mathrm{h}$ & $\mathrm{PE} / \mathrm{g}$ & $\mathrm{PL} / \mathrm{km}$ & $\mathrm{TT} / \mathrm{h}$ & $\mathrm{PE} / \mathrm{g}$ \\
\hline \multirow{21}{*}{$\begin{array}{l}\text { Farms whose fruit } \\
\text { transpor-tation is } \\
\text { affected by typhoon }\end{array}$} & 2 & Donghong & 77.44 & 1.05 & 1542.33 & 89.25 & 1.46 & 1777.51 \\
\hline & 5 & Zhongrui & 109.30 & 1.89 & 2176.97 & 113.85 & 1.95 & 2267.54 \\
\hline & 6 & Zhongjian & 100.02 & 1.89 & 1985.64 & 109.79 & 2.38 & 2179.59 \\
\hline & 10 & Nanfeng & 140.33 & 2.43 & 2794.92 & 211.05 & 3.38 & 4203.36 \\
\hline & 11 & Lingtou & 147.41 & 2.70 & 2926.61 & 225.57 & 3.05 & 4478.15 \\
\hline & 15 & Licai & 299.00 & 4.01 & 5936.12 & 358.51 & 6.71 & 7117.42 \\
\hline & 17 & Jiusuo & 312.43 & 4.56 & 6202.62 & 476.52 & 8.92 & 9460.44 \\
\hline & 18 & Leguang & 236.98 & 4.67 & 4704.71 & 452.14 & 8.47 & 8976.27 \\
\hline & 19 & Xinwei & 152.48 & 2.60 & 3027.09 & 230.63 & 2.97 & 4578.63 \\
\hline & 20 & Weixing & 159.79 & 3.07 & 3172.27 & 177.17 & 3.19 & 3517.39 \\
\hline & 22 & Xipei & 137.87 & 2.44 & 2737.20 & 155.26 & 2.90 & 3082.32 \\
\hline & 23 & Xiqing & 140.20 & 2.63 & 2783.33 & 157.58 & 2.94 & 3128.44 \\
\hline & 24 & Dafeng & 134.19 & 2.71 & 2664.06 & 175.92 & 3.29 & 3492.44 \\
\hline & 25 & Yangjiang & 135.96 & 2.70 & 2699.12 & 172.31 & 3.22 & 3420.96 \\
\hline & 26 & Xinjin & 120.15 & 2.31 & 2385.31 & 346.17 & 6.48 & 6872.49 \\
\hline & 27 & Huangling & 109.05 & 2.08 & 2165.01 & 333.29 & 6.24 & 6616.88 \\
\hline & 28 & Guangqing & 74.82 & 1.31 & 1485.36 & 114.73 & 1.44 & 2277.72 \\
\hline & 29 & Chenxing & 94.97 & 2.08 & 1885.37 & 180.89 & 3.11 & 3591.2 \\
\hline & 30 & Xihua & 157.56 & 2.90 & 3138.02 & 174.94 & 4.31 & 3473.13 \\
\hline & 32 & Guangba & 241.55 & 3.43 & 4795.49 & 380.87 & 4.99 & 7561.44 \\
\hline & 33 & Baolun & 325.90 & 5.03 & 6470.19 & 398.58 & 7.42 & 7913.01 \\
\hline SUM & & & 5898.19 & 94.8 & $117,471.3$ & 7725.69 & 130.2 & $153,868.7$ \\
\hline
\end{tabular}

\subsection{Comparative Experiment between Three Path Optimization Methods}

Due to the significant increase of vehicle emissions under adverse weather, in this sub-section, we take three path optimization methods, i.e., the traditional OLRO method, the MSPO method, and the CEPO method to optimize travelling path for fruit transportation in typhoon scenario, and to study if they can reduce vehicle emissions under adverse weather by path optimization.

Firstly, we optimize a single travelling path from the Baolun farm to Haikou port by three methods in typhoon scenario, and the results are shown in Figures 6-8 (their legends are the same as in Figure 5). Comparing these three methods, we can find that the shortest PL is $280.47 \mathrm{~km}$ by the MSPO method, and the second shortest is $325.9 \mathrm{~km}$ by the CEPO method. Meanwhile, the PL by the OLRO method is 1.42 times the PL by the MSPO method and 1.22 times the PL by the CEPO method. By comparing TT, the TT of the MSPO method is $7.66 \mathrm{~h}$, which is the longest travelling time of the three methods. The shortest TT is $4.9 \mathrm{~h}$ of the CEPO method, which is $36 \%$ shorter than the TT of the OLRO method and $32 \%$ shorter than the TT of the MSPO method. Then, we use three methods to optimize traveling paths for multiple vehicles of long-distance fruit transport from 35 farms to Haikou port in typhoon scenario. Figure 9 shows that the total travelling path length by the MSPO method is $5683.28 \mathrm{~km}$, the CEPO method is $5903.82 \mathrm{~km}$, and the OLRO method is $7492.51 \mathrm{~km}$. The path length of the CEPO method is $21.2 \%$ less than that of the OLRO method, and just 3.8\% more than that of the MSPO method. The longest average travelling time is the TT of the MSPO method $4.87 \mathrm{~h}$, which is $32.9 \%$ more than that of the OLRO method, and $48.8 \%$ more than the CEPO method. The corresponding vehicle emissions 
are calculated as shown in Figure 10. From the perspective of vehicles emission reduction, the MSPO method is optimal, while the CEPO method is not much worse than the MSPO method; in other words, the emission reduction capacities of the two methods are almost the same.

As a result, although the MSPO method is useful to reduce vehicle emissions, the travelling time greatly increases, which is against with transportation efficiency and increase potential travelling risk. The OLRO method takes real-time optimization strategy, but it has no advantage in TT, PL, or PE. Surprisingly, compared with the OLRO method, the CEPO method can not only shorten travelling path and therefore reduce vehicle emissions, but also shorten traveling time. The travelling time by the CEPO method is the shortest, which minimizes the journey risk for drivers under adverse weather, and also well observes the punctuality of logistical industry. Therefore, the CEPO method can provide a better-balanced strategy for path optimization under adverse weather in terms of low journey risk, high punctuality, and low vehicle emissions. In particular, the OLRO method is widely adopted in daily practice of logistical industry, so the experimental results of this sub-section show that the introduction of CEPO method can improve vehicle emissions reduction of logistical industry under adverse weather. According to the case of Hainan island, the pollutant emissions of logistic transportation by the OLRO method under adverse weather are $153.87 \mathrm{t}$. The pollutant emissions of logistic transportation by the CEPO method is $21.2 \%$ less than that of the OLRO method, and just $3.8 \%$ more than that by the MSPO method. So, in the case of Hainan island, we may reduce pollutant emissions by 32.6 tons through transportation path optimization in a single typhoon event. There are tens of adverse weather events like typhoon per year in Hainan Island. There are many areas like Hainan Island worldwide, e.g., the coastal areas of England and other developed countries in Europe, the Yangtze River Delta and Pearl River Delta in China, the Eastern coast of the United States, and the Gulf of Mexico, and they are heavily affected by adverse weather such as typhoon every year. So vehicle emission reductions in adverse weather could be significant on the worldwide scale.

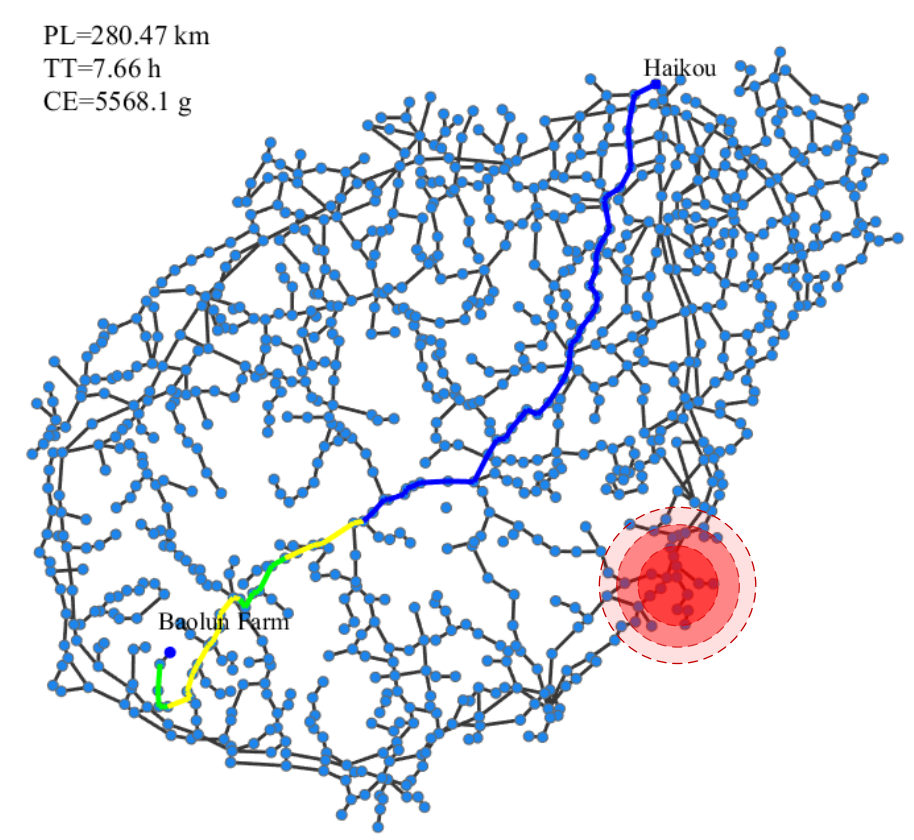

Figure 6. The single path optimization by the modified static path optimization (MSPO) method from Baolun farm under the typhoon. 


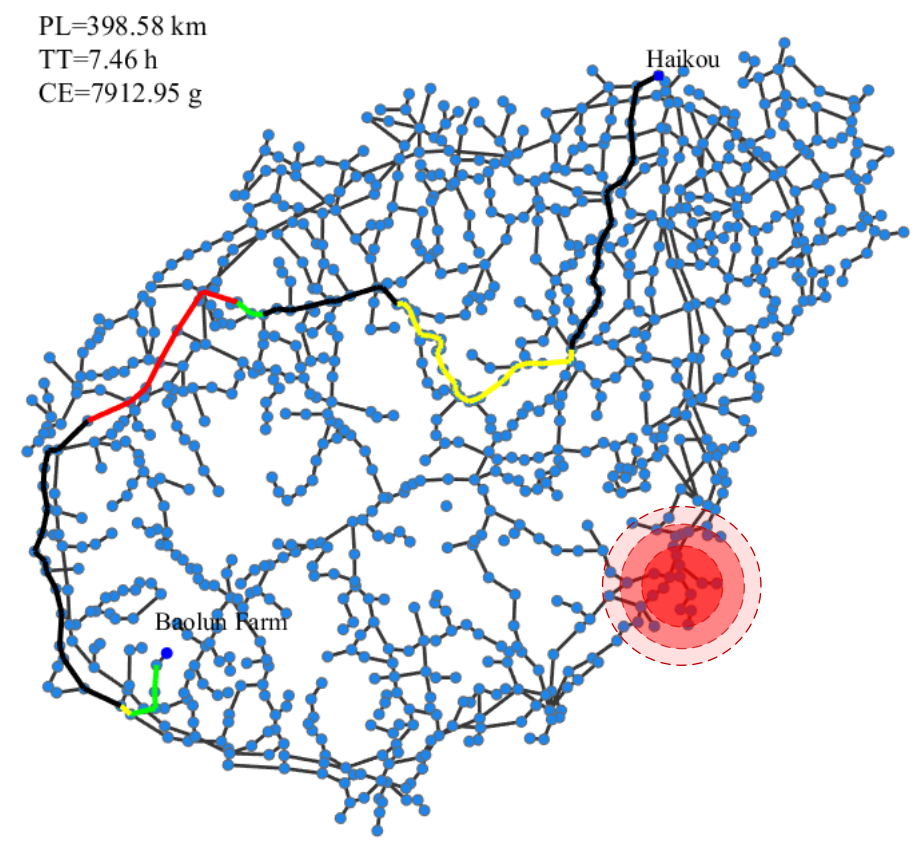

Figure 7. The single path optimization by the OLRO method from Baolun farm under the typhoon.

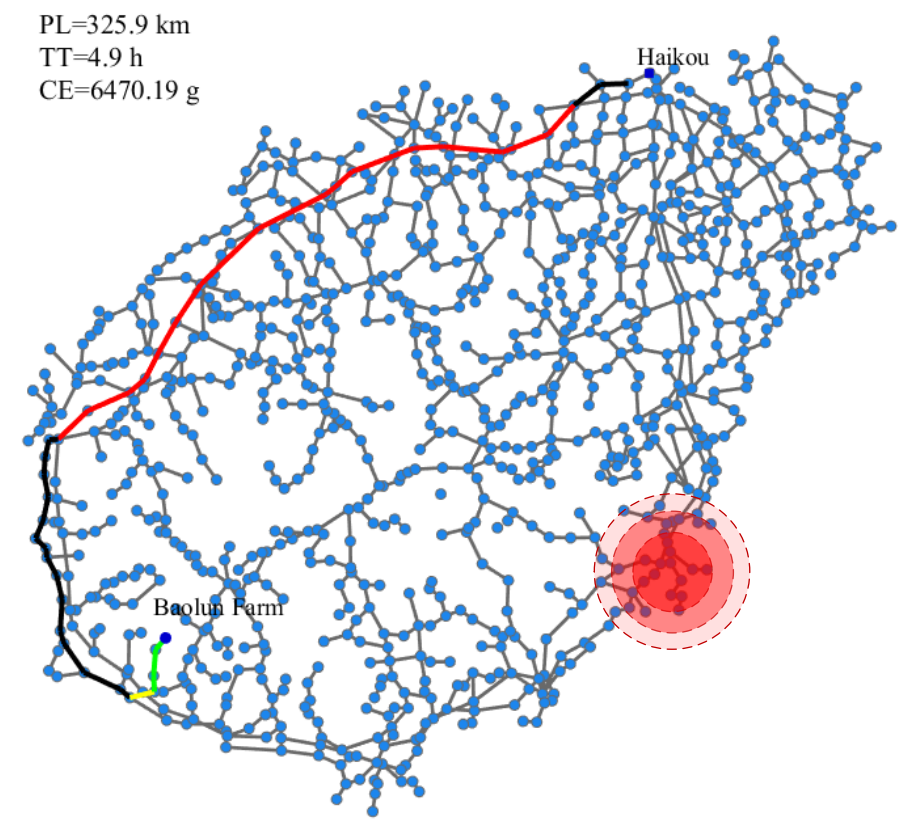

Figure 8. The single path optimization by CEPO method from Baolun farm under the typhoon. 


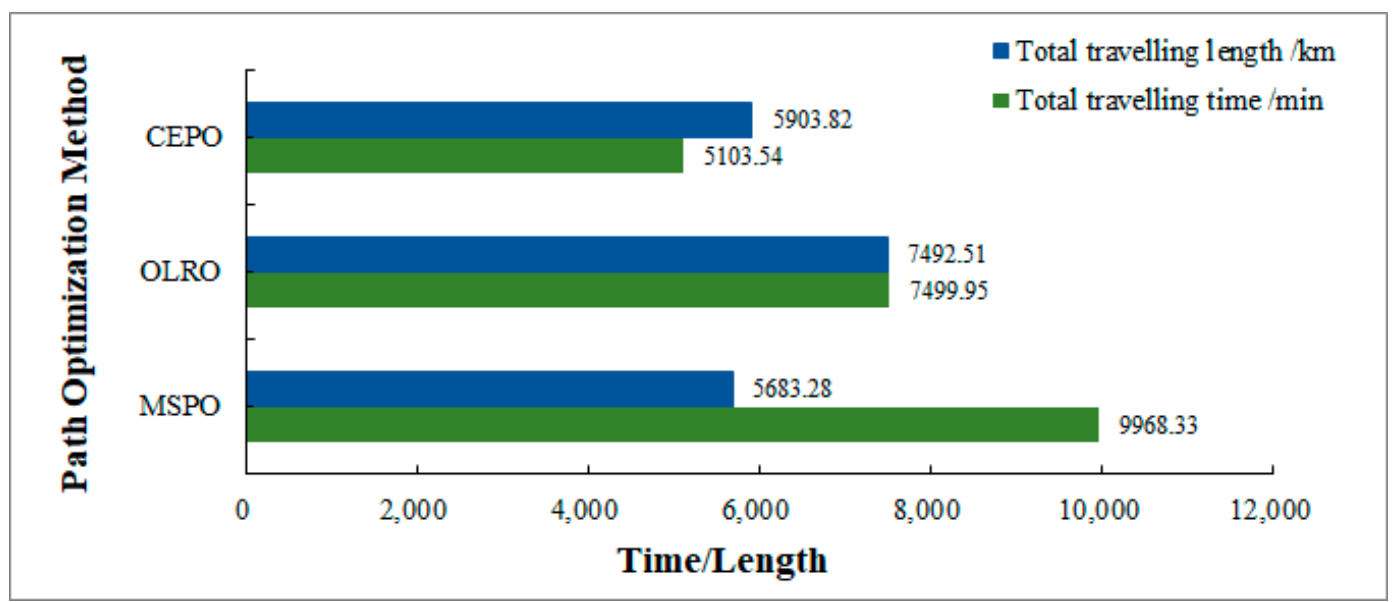

Figure 9. Path optimization results with three methods from 35 farms in the typhoon scenario.

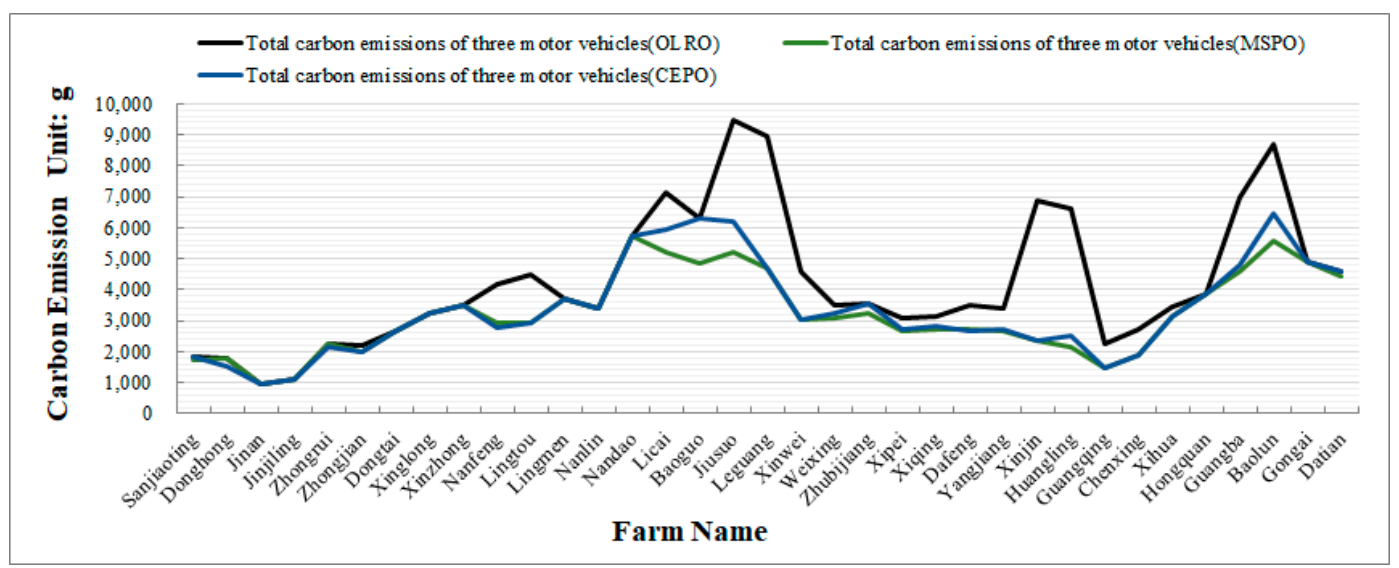

Figure 10. Total vehicle pollutant emissions of three types of vehicles under three methods from 35 farms in typhoon scenario.

\section{Conclusions and Future Work}

This paper explores a new way for eco-driving by optimizing paths for multiple vehicles of long-distance cargo transport under adverse weather, in order to help with the reduction of vehicle emissions under adverse weather. First, we set up a calculation model of pollutant emissions about logistic transportation, called the LT-PE model, to evaluate whether and how much more vehicle pollutant emissions will be produced under adverse weather. The LT-EP model results show that the pollutant emissions of logistics vehicles in adverse weather are about $28.1 \%$ more than that under normal weather, which means there is a great potential to reduce pollutant emissions for logistic transportation under adverse weather. Then, we propose a path optimization-based method to assess and reduce pollutant emission under adverse weather, including two traditional methods, i.e., MSPO method and OLRO method, and a new method, i.e., RSA (ripple-spreading algorithm)-based CEPO method. In a case study of a typhoon scenario in the Hainan island, China, by comparing it with another two widely adopted methods, the new method offers a better way to address the balance between carbon emissions and journey risk.

It may be worth further efforts to expand this research work. (1) Consider more realistic traffic condition for emissions calculation and reduction. How to obtain more real traffic conditions data and establish traffic forecasting model under typhoon would be a good direction for future research. (2) Develop more sophisticated typhoon model by collecting and analyzing more relevant typhoon data, and further improve the proposed CEPO method for future application study. 
Author Contributions: Methodology, X.H. and M.Z.; M.Z. improved the optimization algorithm conducted simulation experiment, and write the original manuscripts; X.H. and J.W. conducted the review and amendment process. X.H. was responsible for the overall writing process.

Funding: This research was funded by Natural Science Foundation of China, grant number No.61472041 and No.41671501 and the Blue-Sky Scholar Research Start-Up Fund from the Civil Aviation University of China.

Conflicts of Interest: The authors declare no conflict of interest.

\section{References}

1. Yuan, Q. Location of Warehouses and Environmental Justice. J. Plan. Educ. Res. 2018, 1-12. [CrossRef]

2. Souleymane, C.; Klaus, D.U. World Development Report 2009: Reshaping the World Boundary Economic Geography; World Bank: Washington, DC, USA, 2009.

3. UNEP. Annual Report of United Nations Enviroment Programme; UNEP: Nairobi, Kenya, 2010.

4. Rice, M.B.; Rifas-Shiman, S.L.; Litonjua, A.A.; Oken, E.; Gillman, M.W.; Kloog, I. Lifetime Exposure to Ambient Pollution and Lung Function in Children. Am. J. Resp. Crit. Care Med. 2016, 193, 881-888. [CrossRef] [PubMed]

5. Hsu, Y.H.; Chuang, H.C.; Lee, Y.H.; Lin, Y.F.; Chen, Y.J.; Hsiao, T.C.; Wu, M.Y.; Chiu, H.W. Traffic-related particulate matter exposure induces nephrotoxicity in vitro and In Vivo. Free Radic. Biol. Med. 2019, 135, 235-244. [CrossRef] [PubMed]

6. Lei, Z.; Bo-Guang, W.; Da-Gang, T. Impact of Heavy-Duty Diesel Vehicles on Air Quality and Control of Their Emissions. Environ. Sci. 2011, 32, 2177-2183.

7. Kerry, E. Increasing destructiveness of tropical cyclones over the past 30 years. Nature 2005, 436, 686-688.

8. Giuliano, G.; O’Brien, T.; Dablanc, L.; Holliday, K. Synthesis of Freight Research in Urban Transportation Palnning; National Academy of Science: Washington, DC, USA, 2013.

9. Wang, H.; Chen, C.; Huang, C. On-road vehicle emission inventory and its uncertainty analysis for Shanghai, China. Sci. Total Environ. 2008, 398, 60-67. [CrossRef]

10. Frances, M. Climate Change and Air Pollution: Exploring the Synergies and Potential for Mitigation in Industrializing Countries. Sustainability 2009, 1, 43-54.

11. NBSC. China Statistical Yearbook; China Statistical Publisher: Beijing, China, 2015. (In Chinese)

12. Yang, F.; Yu, L.; Song, G. Application of small sampling approach to estimating vehicle mileage accumulations for Beijing. J. Transp. Res. Board 2005, 1,77-82. [CrossRef]

13. Peters, J.M. Epidemiologic Investigation to Identify Chronic Effects of Ambient Air Pollutants in Southern California; Department of Preventive Medicine, University of Southern California: Los Angeles, CA, USA, 2004.

14. Giuliano, G.; Dessouky, M.; Moore, J.E., II. Selected Papers from the National Urban Freight Conference. Transp. Res. Part E 2008, 44, 181-184.

15. Webster, P.J. Changes in Tropical Cyclone Number, Duration, and Intensity in a Warming Environment. Science 2005, 309, 1844-1846. [CrossRef]

16. Fang, J.; Sun, S.; Shi, P. Assessment and Mapping of Potential Storm Surge Impacts on Global Population and Economy. Int. J. Disaster Risk Sci. 2014, 5, 323-331. [CrossRef]

17. Gao, B.; Liu, W. Emissions reduction potential analysis of road transportation. Geogr. Res. 2013, 32, 767-775. (In Chinese)

18. Klier, T.; Linn, J. Using Taxes to Reduce Carbon Dioxide Emissions Rates of New Passenger Vehicles: Evidence from France, Germany, and Sweden. SSRN Electron. J. 2015, 7, 212-242. [CrossRef]

19. McKinnon, A.C. The Potential of Economic Incentives to Reduce CO2 Emissions from Cargo Transport. DILF Orienter. 2010, 47, 24-38.

20. Subramaniyam, K.V.; Kumar, C.S.N.; Subramanian, S.C. Analysis of Handling Performance of Hybrid Electric Vehicles. IFAC-Pap 2018, 51, 190-195. [CrossRef]

21. Nienhueser, I.A.; Qiu, Y. Economic and environmental impacts of providing renewable energy for electric vehicle charging-A choice experiment study. Appl. Energy 2016, 180, 256-268. [CrossRef]

22. Igliński, H.; Babiak, M. Analysis of the Potential of Autonomous Vehicles in Reducing the Emissions of Greenhouse Gases in RouteTransport. Procedia Eng. 2017, 192, 353-358. [CrossRef]

23. Sternab, R.E.; Chen, Y.C.; Churchill, M. Quantifying air quality benefits resulting from few autonomous vehicles stabilizing traffic. Transp. Res. Part D Transp. Environ. 2019, 67, 351-365. [CrossRef] 
24. Shancita, I.; Masjuki, H.H.; Kalam, M.A.; Rizwanul Fattah, I.M.; Rashed, M.M.; Rashedul, H.K. A review on idling reduction strategies to improve fuel economy and reduce exhaust emissions of transport vehicles. Energy Convers. Manag. 2014, 88, 794-807. [CrossRef]

25. Stevanovic, A.; Stevanovic, J.; Zhang, K.; Batterman, S. Optimizing traffic control to reduce fuel consumption and vehicular emissions: Integrated approach with VISSIM, CMEM, and VISGAOST. J. Transp. Res. Board 2009, 2128, 105-113. [CrossRef]

26. Barth, M.J.; Wu, G.Y.; Boriboonsomsin, K. Intelligent Transportation Systems and Greenhouse Gas Reductions. Curr. Sustain./Renew. Energy Rep. 2015, 2, 1-8. [CrossRef]

27. Soon, K.L.; Lim, J.M.Y.; Parthiban, R. Coordinated Traffic Light Control in Cooperative Green Vehicle Routing for Pheromone-based Multi-Agent Systems. Appl. Soft Comput. 2019, 81, 105486. [CrossRef]

28. Organ, B.; Huang, Y.; Zhou, J.L.; Surawski, N.C.; Yam, Y.S.; Mok, W.C.; Hong, G. A remote sensing emissions monitoring programme reduces emissions of gasoline and LPG vehicles. Environ. Res. 2019, 177, 108614. [CrossRef] [PubMed]

29. Savković, T.; Miličić, M.; Pitka, P.; Milenković, I.; Koleška, D. Evaluation of the eco-driving training of professional truck drivers. Oper. Res. Eng. Sci. Theory Appl. 2019, 2, 15-26. [CrossRef]

30. Barth, M.; Boriboonsomsin, K. Energy and emissions impacts of a freeway-based dynamic eco-driving system. Transp. Res. Part D Transp. Environ. 2009, 14, 400-410. [CrossRef]

31. Frigioni, D.; Marchetti-Spaccamela, A.; Nanni, U. Fully dynamic algorithms for maintaining shortest paths trees. J. Algorithms 2000, 34, 251-281. [CrossRef]

32. Frigioni, D.; Marchetti-Spaccamela, A.; Nanni, U. Semidynamic algorithms for maintaining single-source shortest path trees. Algorithm Mica 1998, 22, 250-274. [CrossRef]

33. Ding, W.; Qiu, K. Incremental single-source shortest paths in digraphs with arbitrary positive arc weights. Theor. Comput. Sci. 2017, 674, 16-31. [CrossRef]

34. Narvaez, K.S.; Tzeng, H. New dynamic algorithms for shortest path tree computation. IEEE/ACM Trans. Netw. 2000, 8, 734-746. [CrossRef]

35. Idri, A.; Oukarfi, M.; Boulmakoul, A.; Zeitouni, K.; Masri, A. A distributed approach for shortest path algorithm in dynamic multimodal transportation networks. Transp. Res. Procedia 2017, 27, 294-300. [CrossRef]

36. Ramalingam, G.; Reps, T. An incremental algorithm for a generalization of the shortest-path problem. J. Algorithm 1996, 21, 267-305. [CrossRef]

37. Sheng, Y.; Gao, Y. Shortest path problem of uncertain random network. Comput. Ind. Eng. 2016, 99, 97-105. [CrossRef]

38. Baue, R.; Wagner, D. Batch dynamic single-source shortest-path algorithms: An experimental study. Exp. Algorithms 2009, 5526, 51-62.

39. Taoka, D.; Takafuji, T.; Watanabe, T.I. Performance comparison of algorithms for the dynamic shortest path problem. IEICE Transactions on Fundamentals of Electronics. Commun. Comput. Sci. 2007, 847, 847-2007.

40. Paul, B. Rerouting shortest paths in planar graphs. Discret. Appl. Math. 2017, 231, 95-112.

41. Hu, X.B.; Zhang, M.K.; Zhang, Q.; Liao, J.Q. Co-evolving path Optimization by Ripple-Spreading Algorithm. Transp. Res. Part B Methodol. 2017, 106, 411-432. [CrossRef]

42. Hu, X.B.; Wang, M.; Leeson, M.S.; Hines, E.L.; Di Paolo, E. Deterministic Agent-Based Path Optimization Method by Mimicking the Spreading of Ripples. Evol. Comput. 2016, 24, 319-346. [CrossRef]

43. Xie, R.F.; Chen, Z.B.; Deng, X.K. Characteristics of Motor Vehicle Pollutant Emission and Share Ratio in Haikou City Based on MOVES2014a. Nat. Sci. J. Hainan Univ. 2017, 35, 87-94. (In Chinese)

44. Hu, X.B.; Wang, M.; Hu, D.; Leeson, M.S.; Hines, E.L.; Di Paolo, E. A Ripple-Spreading Algorithm for the k Shortest Paths Problem. In Proceedings of the 2012 the 3rd Global Congress on Intelligent Systems, Wuhan, China, 6-8 November 2012; pp. 202-208.

45. Hu, X.B.; Sun, Q.; Wang, M.; Leeson, M.S.; Hines, E.L.; Di Paolo, A. Ripple-Spreading Algorithm to Calculate the k Best Solutions to the Project Time Management Problem. In Proceedings of the 2013 IEEE Symposium Series on Computational Intelligence (IEEE SSCI 2013), Singapore, 16-19 April 2013.

46. Deng, C.; Zhang, X.Q.; Liu, Y. Status analysis and development strategy of Harbor logistics industry in Hainan. Humanit. Soc. Sci. J. Hainan Univ. 2012, 30, 124-130. (In Chinese)

47. Kunkel, K.E.; Easterling, D.R.; Kristovich, D.A.; Gleason, B.; Stoecker, L.; Smith, R. Recent increases in U.S. heavy precipitation associated with tropical cyclones. Geophys. Res. Lett. 2010, 37, 701-719. [CrossRef] 
48. Malmstadt, J.C.; Elsner, J.B.; Jagger, T.H. Risk of strong hurricane winds to Florida cities. J. Appl. Meteor. Clim. 2010, 49, 2121-2132. [CrossRef]

49. China Meteorological Administration, Grade of Weather Conditions for Freeway Transportation; China Meteorological Press: Beijing, China, 2010.

(C) 2019 by the authors. Licensee MDPI, Basel, Switzerland. This article is an open access article distributed under the terms and conditions of the Creative Commons Attribution (CC BY) license (http://creativecommons.org/licenses/by/4.0/). 